\title{
Research on the Realizing Path of Colleges and Universities "Micro-Culture" Playing the Positive Guiding Function
}

\author{
Xuesong Liu
}

JiLin Agricultural Science and Technology University, Jinlin, 132101

Keywords: Realizing Path, Colleges and Universities, "Micro-Culture", Positive Guiding Function

\begin{abstract}
Micro-culture has both positive and negative effects on ideological and political education in colleges and universities. The ideological and political education work in colleges and universities should focus on the micro-culture positive guidance function, guide students to correctly understand micro-culture, build a good education platform, and regularly carry out "micro-activities" to enhance students' ability to distinguish between right and wrong and promote students' moral literacy.
\end{abstract}

\section{Introduction}

In recent years, words such as Wei-bo, We-Chat, micro-course, micro-video, micro-public welfare, etc. have gradually become hot words, especially Wei-bo, We-Chat, and micro-classes are rapidly spreading. With regard to the definition of micro-culture, "Micro-Philosophy" suggests that micro-culture is a power of savings, which is insignificant but quietly changes human life. At the same time, some scholars believe that micro-culture is not only logically small, but also its micro-form is also distinctive. Although the academic community has not yet given a unified definition of micro-culture, the author believes that this kind of culture is characterized by Wei-bo and We-Chat, with the form of "micro-mou", with the characteristics of conciseness, simplification, and smallness. The new style is micro culture. As an important business card for the current social and cultural development, the emergence of micro-culture is the result of social and cultural development, scientific and technological progress, knowledge information expansion, and communication technology innovation. It is also the result of accelerated human life rhythm, cognitive adjustment and psychological needs. Like the same trend of thought, the popularity of micro-culture seems to be completed quickly overnight, and it not only affects people's learning style, lifestyle, but also changes the entire social ecology, which naturally includes school education. The infiltration of micro-culture in school education is not only the embodiment of the inherent influence of social culture on all walks of life, but also the response of the special development logic of school education to culture.

Micro-culture is the cultural manifestation of the interaction of the public in the modern society using the micro-media platform. Micro-culture is also the main component of modern college students' group culture. Ideological and political education discourse should combine the characteristics of micro-cultural discourse to achieve close association with college students, so as to more effectively exert ideological and political education functions and give positive guidance to college students.

\section{The Meaning and Characteristics of Micro Culture}

The concept of "micro-culture" was first proposed by the micro-singer lead singer in the 1990s. In July 1997, he formed a band named "micro". With the sudden rise of Sina Wei-bo, the concept of "micro-culture" and "micro-era" has also appeared on the Internet and has been applied and disseminated. After that, micro-public welfare, We-Chat, micro-movie, micro-speaking, micro-payment, micro-expression, micro-advertising and other series of micro-cultures marked by "micro" became an important cultural form and value concept without knowing it. And lifestyle" [1]. It not only has the characteristics of wide range and fast speed of new media represented by the 
network, but also has the characteristics of various modes of communication, such as multi-portability, timely information transmission and timely interaction.

"Micro" was elected as the annual Chinese character with more than 400,000 votes in the "2011 Cross-Strait Annual Chinese Characters" campaign hosted by the cross-strait media in 2011 [2]. The micro-culture represented by Wei-bo, We-Chat, Minor, and Micro-Public Welfare has the common feature of a micro-character. Micro-culture often achieves information exchange, viewpoint expression and content sharing through short and precise text or pictures. In addition, Wei-bo, We-Chat and other convenient and fast, self-media-based hosting and dissemination methods make information transmission and communication speed more convenient and faster.

Micro-culture has the characteristics of timely and time-sensitive information that is not available in the old media. Through public social platforms such as Wei-bo and We-Chat and instant messaging tools, we can forward and share information in a timely manner. Everyone is a communicator of information and news. People can transmit, update and share information in the first time. The information is very time sensitive and immediacy.

The application of social and timely communication software such as Wei-bo and We-Chat has no class, race, ethnicity, hierarchy, rich or poor, and the subject and object. Everyone has the right to use. Everyone is "self-media" and can pass them. To communicate, communicate, exchange and share information. The dissemination of information and culture is carried out in various ways, such as texts, pictures, and micro-videos. The styles, words, and contents can be edited and created according to their own moods, moods, what they see and hear, and what they think. Originality and personalization can be fully utilized. People can also choose their own content or information that is of interest or beneficial to satisfy their own spiritual needs according to their own preferences. Compared with the traditional one-to-many, traditional and object-specific traditional media, micro-culture makes people's subjectivity respect and enhance. .

Strong interactivity and open microcultural communication set creation, comment, forwarding, and attention. Anyone can participate in the review, forwarding, and discussion of information, and can realize the freedom of information compilers and other participants. Exchange and discussion, to achieve the "zero distance" and "zero gap" interaction, reflecting the strong interactivity and openness [3].

\section{The Impact of Micro-Culture on Ideological and Political Education in Colleges and Universities}

In the continuous development of the Internet, people have created micro-cultures such as Wei-bo, We-Chat, micro-payment, and micro-public welfare. The emergence of micro-culture has facilitated people's lives and work, satisfied entertainment needs, and enriched people's spiritual life. It has gradually changed people's traditional living habits and ways of thinking. Under the background of micro-culture, rationally using micro-culture to carry out ideological and political education in colleges and universities is an inevitable requirement under the development of the times.

Micro-culture provides a variety of carriers for the development of ideological education in colleges and universities. The content and functionality of micro-culture are very comprehensive and can provide a variety of ideological and political education carriers for colleges and universities. For example, colleges and universities can establish We-Chat public accounts, publish and publicize positive and positive ideological education content on public accounts, so that college students can subtly accept these information educations under the daily information push. Micro-culture influences the life and learning of college students, and brings convenience to their lives, so that they can break free from the framework of textbooks and obtain information from various channels through mobile devices such as mobile phones and tablets.

Micro-culture can promote the dissemination of ideological education in colleges and universities. The micro-culture derived from the Internet has a huge spread and appeal. Students can learn about the news, entertainment events, campus activities, etc. that happened on the same day through a mobile phone. They can also carry out mobile payment, mobile phone public welfare, etc. 
Activities, through a mobile phone, can be connected to the world. The emergence of micro-culture has broken through time, region and gender constraints, and the power of communication is unimaginable. Nowadays, college students are very fond of micro-culture. With micro-culture for ideological and political education, education can be spread more quickly.

The convenience brought by micro-culture to the ideological and political education work in colleges and universities. Micro-culture has a strong communication platform that enables more people to communicate and communicate, and effectively improve students' communication skills. Many students have discussed hot news on Wei-bo, published their own personal opinions, and actively communicated with other people on Wei-bo platform, reflecting personal value [4].

Micro-culture can make the ideological and political education work of colleges and universities more "grounded". The wide application of Wei-bo and We-Chat has narrowed the distance between people and realized the exchanges of different races, different times and places, and narrowed the scope of the world. In the ideological education work of colleges and universities, micro-culture can enable students to feel ideological education anytime and anywhere, and make the education work more grounded and welcomed by students.

\section{The "Micro-Culture" of Colleges and Universities to Play the Realization Path of the Positive Guidance Function}

"Strengthen and improve the construction of online content, sing the main theme of the Internet. Strengthen the management of network society and promote the regular and orderly operation of the network according to law", which is the basic requirement of the Party Central Committee for the education of the socialist core values of the university students. It is also a guiding program for actively exerting the function of micro-culture carrier, evading the negative influence of micro-culture, and continuously enhancing the educational effectiveness of college students' socialist core values. It is necessary to continuously enhance the effectiveness of college students' socialist core values education. First, the state should improve network legislation, establish and improve network laws and regulations, form an effective control mechanism, and purify the microcultural environment. Second, optimize the microcultural ecology and give play to the network's thinking on college students. The correct guiding function of behavior makes the Internet become a new platform and new channel for understanding students, being close to students and improving their healthy development. Third, universities should strengthen campus network supervision, purify campus network environment and micro-culture environment, and build positive and healthy. Civilized campus micro-cultural atmosphere; Fourth, strengthen the network moral education of college students, guide them to be more self-disciplined in the virtual micro-cultural world, conscientiously abide by ethical norms and laws and regulations, do not believe, do not pass on, away from cyber violence and cybercrime, Start from yourself and actively practice online ethics [5].

The micro-culture represented by We-Chat and Wei-bo has become an important carrier for college students' life, study and daily communication, and an elected medium for educating them on socialist core values. In order to continuously enhance the educational achievements of socialist core values, colleges and universities must actively seize the commanding heights and main positions of Wei-bo and We-Chat, and follow up and innovate Marx in a way that conforms to the trend of the times and the love of college students by means of praise, interaction, regular push, and real-time update. The popularization of the theory of theory and the educational methods of socialist core values, constantly improving the disciplinary system, academic system and discourse system guided by Marxism, and putting an end to Marxist theory and socialist core values, "being marginalized, empty, and labelled, In some disciplines, 'aphasia', 'missing' in textbooks, and 'missing' in forums. At the same time, we must continuously strengthen the party's leadership, management, and discourse power over the ideological work of colleges and universities. In particular, we must enhance our initiative and take the initiative in matters of persistence or denial of the four basic principles. "Protect the initiative to help", to help college students "clear the boundaries between right and wrong, and clarify vague understanding". 
With the development of micro-culture, micro-movies and micro-videos that incorporate many fashion trends, commercial customization, humorous and public welfare education are sought after by college students with artistic language and ups and downs. Scientifically and rationally utilizing the new carrier of micro-movie and micro-video to carry out the positive function of college students' socialist core values education, their hearts can be touched in the vivid audio-visual feast, the thoughts resonate, and the behavior can be guided and regulated. In addition to watching micro-movies, colleges and universities should also cultivate and enhance their patriotism, dedication, integrity, friendliness and freedom, equality, justice and the rule of law through students' self-made scripts, self-directed micro-movies and micro-videos.

Micro-public welfare is the abbreviation of micro-public welfare. "It refers to starting from a trivial public welfare event, emphasizing the public welfare behavior that consists of less and more, and weaker and stronger. It can bring people's love branches together and become a powerful one. Micro-public welfare makes full use of the immediacy, grassroots and popular characteristics of micro-cultures, disseminates public welfare concepts, exchanges public welfare spirit, optimizes public welfare environment, regulates public welfare behaviors through micro-blogs, We-Chat and other micro-channels, and realizes public welfare. These micro-public welfare activities can not only resolve the credibility crisis brought by traditional public welfare, but also help to cultivate college students' sense of honesty, good heart and charity spirit, enhance the spiritual realm of the "online moral self" of college students and the subject consciousness, and continue to enhance them. The sense of historical mission and social responsibility have motivated them to participate more actively in the practical actions of promoting national prosperity, political enlightenment and social harmony, thereby helping to enhance their concept of "patriotism, dedication, honesty and friendliness". Integrate micro-philanthropy into the campus life, form a public welfare campus and a public welfare culture, so that the socialist core values are deeply rooted and steadily growing on the university campus.

\section{Conclusion}

Under the continuous development of Internet technology, colleges and universities should strengthen their links with Wei-bo and We-Chat, be good at expressing their own ideas and ideas in micro-media, promote the core values of socialism, and provide students with timely and correct information to enhance students' right and wrong.

\section{Acknowledgements}

Fund Project: 2015 Twelfth Five-Year Plan for Education Science in Jilin Province, Contract No.: GH150411

\section{References}

[1] Xi Jinping. The overall layout of all parties to coordinate innovation and development efforts to build China into a network power [N]. People's Daily, 2014 - 02 - 28 (1).

[2] Yu Anlong, Liu Wenjia. The influence of micro-culture on the education of college students' socialist core values and its countermeasures [J]. Chinese Youth Research, 2014(11): 107.

[3] Li Feng. Micro-culture: The new darling of the all-media era [J]. The World of News, 2012 (2): 75 .

[4] Zhang Chunmei. Cultivation of Socialist Core Values under Microcultural Ecology[J]. Journal of Anhui Normal University(Humanities and Social Sciences),2014,(1).

[5] Wei Jingrong. Micro-culture and College Students' Ideological and Political Education [J]. New West, 2013, (21) 162-163. 